\title{
Familiar friend or alien stranger? On translating the Bible
}

The Bible is both a collection of diverse ancient texts, written in various ancient languages, and the canon, the authoritative scriptures (in various forms) of the contemporary Christian churches. That much is, of course, obvious. But this dual identity raises specific questions about what translations of the Bible ought to aim to do. How do various conventions of translation affect the ways in which the biblical text strikes those who read and encounter it in translation? Focusing here on examples from the New Testament, particularly from the NRSV and the NIV, probably the two most widely used modern translations, ${ }^{1}$ I shall suggest that modern translations ought to do more justice to the Bible's rootedness in ancient culture, its often strange and puzzling difference from 'us', its sometimes enigmatic and unclear expression, and thus press readers to see the text more 'as it is' rather than as a text (or rather, collection of texts) which rather neatly dovetails with contemporary Christian assumptions. This is not intended, as we shall see in conclusion, to undermine theological or devotional use of the Bible, but rather to enable readers who depend on translations to develop a more 'honest' encounter with the text, closer, in fact, to that experienced by those who read it in its original languages.

\section{Formal and dynamic equivalence}

This opening salvo must not be mistaken as a naïve call for more 'literal' translations. Translation from one language to another - which also inevitably means 'translation' from one culture to another - always involves and requires interpretation. Although there are valid distinctions, then, between approaches commonly labelled 'formal equivalence' and 'dynamic equivalence', it must be stressed that the distinctions are more like points on a sliding scale than contrasting alternatives. Earle Ellis, in a recent article in this journal, argues for a formal equivalence approach, which he defines as an “"essentially literal” procedure, translating as closely as possible the original words and

\footnotetext{
${ }^{1}$ I shall also pay some limited attention to more recent versions, notably the NIV Inclusive Language Edition (NIVI) and the English Standard Version (ESV).
} 
phrases with precise equivalents in English'. ${ }^{2}$ This contrasts with the dynamic approach, reflected for example in the NIV, in which the original is transformed, 'if need be... into what the translator believes would be an equivalent idiom in the modern language and culture' ${ }^{3}$ Ellis criticises the latter approach on various grounds, including that 'it rejects the verbal aspect of biblical inspiration... that for the New Testament authors the divine message... extends to the words they use', and that it 'assumes that the present-day translator knows what contemporary words, idioms and paraphrases are equivalent to the prophets' and apostles' wording'. ${ }^{4}$ The first point could stand - and in the past did stand - as a reason not to translate the Bible at all. If authority and inspiration inhere in the actual words of the sacred text, how can they possibly be translated? The second point merely identifies something essential for all work of translation. If we do not know what words or phrases are equivalent to the words of the source language, then we simply cannot render them into our tongue.

Indeed, any translation must involve a degree of dynamic equivalence. Even when translating, say, from one modern European language to another, where the cultural distance is a great deal less than in the case of translating the Bible, there can never be a one-for-one correspondence. To take the simplest of examples: how could one translate into English 'literally' the German auf wiedersehen or the French au revoir? Each is more or less formally equivalent to the other, but there is no formal equivalent in English, or at least, none used with the same frequency in comparable social contexts. Any translator into English must have a good sense of what 'words, idioms and paraphrases' are equivalent to those used by German and French speakers in order to translate such phrases appropriately. But precisely because translation is an interpretative art, it is important to reflect on how it is best done, and on what kinds of considerations should influence the process. In the special case of the Bible, there are 'religious' reasons which heavily influence the process of translation - sometimes, I shall suggest, to the detriment of a genuine encounter with the text.

\footnotetext{
${ }^{2}$ E. Earle Ellis, 'Dynamic Equivalence Theory, Feminist Ideology, and Three Recent Bible Translations', ExpTim 115 (2003) 7-12; here p. 7.

${ }^{3}$ Ellis, 'Dynamic Equivalence Theory', 7.

${ }^{4}$ Ellis, 'Dynamic Equivalence Theory', 8.
} 


\section{Shared language or special language?}

One of the great and lasting gains of the papyrological and other studies undertaken in the late nineteenth and early twentieth centuries by scholars such as Adolf Deissmann is to have proven decisively that the Greek of the New Testament is no extraordinary, sacred Greek, but simply the common, everyday Greek of the period, so-called koine Greek. ${ }^{5}$ The question remains, however, how to translate some terms of everyday vocabulary, used with a particular sense in the New Testament. One example is the word ekklessia, consistently rendered in the NIV, NRSV, and most other translations, as 'church' (e.g. Matt 16.18; 1 Cor 1.2; 2 Cor 1.1, etc.). To modern ears, the word 'church' can only mean a Christian church, either a special building or a congregation of Christian people. The word ekklessia, however, was commonly used in ancient Greek to refer to assemblies, specifically the (political) assembly of voting citizens in a city-state, or polis. It was also used - though less frequently than the word synagog $\bar{e}$ — in the Greek translation of the Hebrew scriptures to render the Hebrew word qahal, used to refer to the assembly of God's people, the Jews. The unfortunate implications of the translation 'church' are at least twofold: first, the impression is conveyed that the writer is using a word which refers specifically and exclusively to a gathering of Christian people (or to their building: though no dedicated Christian buildings existed in New Testament times, nor for some time thereafter). ${ }^{6}$ Second, the translation 'church' creates the impression that the Christian gatherings were something distinctively 'religious', rather like our sense of church. Thus the translation 'church' implies and reinforces modern presuppositions about the separation of religion and politics, and creates the impression that the writers were using a distinctive term to refer to the Christian gatherings. A translation like 'assembly', on the other hand, would at least allow the reader to see that a common, everyday word is used here, and thus to consider the Christian assemblies as gatherings in

\footnotetext{
${ }^{5}$ Adolf Deissmann, Light from the Ancient East (London: Hodder \& Stoughton, 1910), 62: 'The New Testament has proved to be, as a whole, a monument of late colloquial Greek, and in the great majority of its component parts a monument of the more or less popular colloquial language.'

${ }^{6}$ On the gradual development of church architecture, see L. Michael White, Building God's House in the Roman World: Architechtural Adaptation Among Pagans, Jews and Christians (Valley Forge, PA: TPI, 1996).
} 
some sense comparable with, or even challenging to, other socio-political-religious assemblies in their time. ${ }^{7}$ At least it would avoid conveying anachronistic connotations to the same degree as 'church'. A similar consideration applies to a word like episkopos, which the NRSV translates with the specifically Christian word 'bishop' (Phil 1.1; 1 Tim 3.1-2) rather than with the everyday word 'overseer'. ${ }^{8}$ This point is, of course, somewhat complicated by the fact that words such as ekklessia and episkopos do over time come to acquire a distinctively Christian sense, to describe specifically Christian institutions. But since the New Testament texts reflect the earliest 'Christian' generations - before, indeed, the word 'Christian' had acquired any common currency ${ }^{9}$ - the use of distinctively Christian terms like 'church' is almost certainly anachronistic.

Other specific examples of translations obscuring the extent to which the New Testment uses words and reflects customs prevalent in the ancient culture can easily be added. For example, at Gal 1.8-9 the NIV (and NIVI) translates Paul's repeated phrase anathema estō 'let him be eternally condemned', despite giving the rendering 'be cursed' for anathema at 1 Cor 12.3. Even if the translation of Gal 1.8-9 conveys a general sense not too far from what Paul might have intended, by losing the language of cursing the NIV fails to alert readers to the specific conventions at work here: Paul operated in a world in which people frequently cursed those against whom they had grievances, often by placing curse tablets mentioning the target of their hostility in the ground at a religious shrine. ${ }^{10}$ We may well find such practices and the values they represent difficult and uncongenial, but that is precisely an illustration of the cultural distance between our world and Paul's.

\footnotetext{
${ }^{7}$ Cf. Richard A. Horsley, 'General Introduction', 1-8 (here, p. 8); '1 Corinthians: A Case Study of Paul's Assembly as an Alternative Society', 242-52, both in idem, ed., Paul and Empire (Harrisburg, PA: TPI, 1997).

${ }^{8}$ The NIV has 'overseer', with a footnote: 'or bishop'.

${ }^{9}$ It appears only three times in the New Testament: Acts 11.26; 26.28; 1 Pet. 4.16.

${ }^{10}$ See further Bruce W. Winter, After Paul Left Corinth: The Influence of Secular Ethics and Social Change (Grand Rapids, MI: Eerdmans, 2001) 164-83.
} 


\section{Clear or puzzling? On improving a writer's style}

Another general issue of translation is whether, and when, one should improve the style of the original in the process of translating. Word order, grammatical construction, and so on, cannot of course be simply reproduced but need to be rendered in ways suitable to the target language. ${ }^{11}$ But there are questions as to how far a translator should reproduce the style, the awkwardness, and even the mistakes of the original. The temptation to 'improve' the original should, I suggest, be resisted. If one were to translate a letter written by a nine year old child, the character of the communication and of its author would be completely lost if one 'improved' the prose such that its form and content had a smoothness appropriate to an adult. Yet the biblical texts are often subject to such improvement, with enigmatic or incomplete phrases spelt out, unspecified subjects specified, and so on.

Numerous instances could be supplied. For example, in Mark 14.20 Jesus refers to ho embaptomenos met' emou eis to trublion. There is no mention as to what this person dips into the bowl. But the NRSV and NIV specify 'bread' (as do ESV and NIVI). This may be a reasonable presumption, especially in the light of v. 22 (and cf. John 13.26-30); but it is not what the Greek says, and other things might well have been dipped. $^{12}$

Mark 1.40-45 is a text rather notoriously lacking in specification of the subject: Mark simply repeats 'he' and 'him', leaving it to the reader to discern whether he is talking about Jesus or the leper. But here, as in many other comparable passages, translations regularly specify the subject, adding 'Jesus' to make clear who is acting (NIV adds 'Jesus' in vv. 41, 43, and 45; NRSV in vv. 41 and 45; ESV in vv. 43 and 45). Perhaps it is legitimate to 'help' the reader in this way, but hearers of Mark in Greek

\footnotetext{
${ }^{11}$ And sometimes this inevitably means that some of the beauty and force of the original is lost, as in Mark 5.25-27, where a string of participles describing the woman's predicament finally culminates in an indicative verb, heppsato, 'she touched' (v. 27). Because of the very different usage of participles in Greek and English, the literary character of the Markan text can (unfortunately) hardly be reproduced.

${ }^{12}$ Charles Cranfield, for example, comments: 'The tru\&blion is probably the dish containing the sauce ( $h^{a}$ rôset) of dried fruits, spices and wine or vinegar, in which the bitter herbs were dipped at the Passover meal' (C.E.B. Cranfield, The Gospel According to Saint Mark [CGTC; Cambridge: CUP, 1959] 424).
} 
would not have had such assistance; put differently, the literary style of the original is not to specify the subject, while English translations almost universally choose to do so.

Another well-known feature of Mark's style is his repetitive use of kai euthus. But when the repetition gets too much, or the context seems ill-suited to such a phrase, translations omit it, as do the NRSV and NIV at Mark 1.21, or use various phrases like 'just then', 'as soon as', or 'at that moment' (Mark 1.23, 1.29; 14.72; cf. also 4.5, etc.) to alleviate repetition. Naturally, translation must involve a certain flexibility; as we have already noted, simple one-for-one correspondence is seldom possible. One may understand the desire of translators to ensure that a modern translation has "clarity and literary quality and so prove suitable for public and private reading' ${ }^{13}$ But there is a question as to how far readers of the Bible in English should be enabled (or forced!) to read a text with something like the same 'literary quality' — the same degree of awkwardness, ambiguity, and opacity — as exists for a reader of the original language. More specifically, should a reader of Mark's gospel in English not encounter the text with all the repetitiveness and stylistic simplicity of the Greek, within the limits that translation allows?

Translations are, indeed, often subject to the temptation to 'clarify' the meaning of ambiguous or enigmatic texts. For example, Paul's notorious declaration that kephale de gunaikos ho aner (1 Cor 11.3) — 'and the head of the woman is man' (NIV/NIVI); 'and the husband is the head of his wife' (NRSV) - leaves a reader of the Greek text wondering what exactly is conveyed by the term kephale, 'head'. Translators cannot of course avoid important decisions that affect how a reader of English encounters this text: the Greek words anēr and gunē can equally well mean 'man' and 'woman' or 'husband' and 'wife', so a considered decision must be made as to which is more likely intended here. ${ }^{14}$ But it is unnecessary to succumb to the temptation to spell out what one may judge to be the intended sense implied by kephale. NIV and NRSV commendably leave

\footnotetext{
${ }^{13}$ NIV Preface, p. vi (The Holy Bible, New International Version, London: Hodder and Stoughton, 1979).

${ }^{14}$ I happen to agree with the NIV that 'man' and 'woman' is more likely here, since Paul sets his argument in the context of the Genesis creation stories and seems to be concerned about the generic relation between men and women rather than the more specific nature of marital relations (see vv. 7-9; Gen 1.26-27; 2.7, 20 24). The NRSV might perhaps reflect a desire to limit the sphere of applicability of this text.
} 
the text as open for the English reader as for the Greek, with the straightforward translation 'head'. Scholars continue to debate whether this might be meant in the sense of 'source' (as in the head of a river), ${ }^{15}$ or 'authority over', ${ }^{16}$ or 'preeminence', ${ }^{17}$ and so on. But the GNB lessens the scope for English readers to ponder the possible meanings of the text, and gives the interpretation 'the husband is supreme over his wife'. A similar issue concerns the translation of 1 Cor 11.10 , where the Greek rather enigmatically states that a woman should have exousian... epi tēs kephalès, 'authority on her head'. Commentators have long presumed — almost certainly incorrectly ${ }^{18}$ — that Paul must mean that the woman's head covering is a symbol of her being under authority; ${ }^{19}$ some translations have likewise interpreted and expanded the words. The NJB, for example, states that 'a woman must wear on her head a sign of the authority over her'. Whether these kinds of rendering give the correct interpretation is beside the point: texts which in Greek are open to a range of possible meanings have been rendered in such a way as to close off to English readers the opportunity to see and explore these possibilities. Of course, it is more 'confusing' for readers to read a text that leaves open the possibilities of interpretation, that leaves a text enigmatic. But given that readers without Greek and Hebrew already and unavoidably must blindly trust the translators, the latter should resist

${ }^{15}$ E.g. S. Bedale, 'The Meaning of kephale in the Pauline Epistles', JTS 5 (1954) 211-15; Robin Scroggs, 'Paul and the Eschatological Woman', JAAR 40 (1972) 283-303, here 298-99 n.1; Gordon D. Fee, The First Epistle to the Corinthians (NICNT; Grand Rapids, MI: Eerdmans, 1987) 502-504.

${ }^{16}$ E.g. Wayne Grudem, 'The Meaning of kephalē (“Head”): A Response to Recent Studies', Trinity Journal 11 (1990) 3-72; Joseph Fitzmyer, 'Kephalē in 1 Corinthians 11:3', Int 47 (1993) 52-59.

${ }^{17}$ E.g. A.C. Perriman, 'The Head of a Woman: The Meaning of KEPHALE in 1 Cor. 11:3', JTS 45 (1994) 602-22; R.S. Cervin, 'Does Kephalē Mean “Source” or “Authority Over” in Greek Literature? A Rebuttal', Trinity Journal 10 (1989) 85-112.

${ }^{18}$ See M.D. Hooker, 'Authority on Her Head: An Examination of 1 Cor. XI. 10', NTS 10 (1964) 410-16, reprinted in From Adam to Christ: Essays on Paul (Cambridge: CUP, 1990) 113-20.

${ }^{19}$ Particularly revealing is the comment of Archibald Robertson and Alfred Plummer, writing in 1914: 'Why does St Paul say “authority” when he means "subjection”?' (A Critical and Exegetical Commentary on the First Epistle of St. Paul to the Corinthians [2nd edition; Edinburgh: T\&TClark, 1914] 232. They proceed, it should be noted, to consider other possible interpretations, but appear convinced that ' $[\mathrm{t}] \mathrm{here}$ is no real doubt as to the meaning' (p. 232). 
the temptation to control interpretation, to muzzle the text, by foreclosing its meaning in the process of translation.

\section{Sexist or non-sexist? Coming to terms with patriarchal texts}

The issue of inclusive language in translation and liturgy continues to be the subject of heated debate, which I shall not explicitly engage here $;{ }^{20}$ many complex and involved questions must remain unexplored. Perhaps the key issue in relation to the focus of this article is whether or not translations should obscure the androcentric and patriarchal character of the original texts and the cultures they reflect. ${ }^{21}$ Different types of cases require different treatment, in my view. One type concerns instances where the Greek anthrōpos or the Hebrew 'àdām are used. Both Greek and Hebrew have two words for what was traditionally rendered 'man', one which distinguishes man from woman (Gk: anēr, Heb: ‘iyš), another which distinguishes human from non-human (Gk: anthrōpos, Heb: 'ādām). Since 'man' is increasingly coming to be regarded, not least due to feminist critique, as an inappropriate label to refer generically to human beings, there is a strong case for translating anthrōpos and 'àdām with non gender-specific terms such as 'person', 'human being', and so on. Such translations simply mark in English a distinction already made in Hebrew and Greek. Indeed, there is no translation-based reason, aside from conventional attachment to certain labels, why phrases like 'the son of man' (ho huios tou anthrōpou) should not be rendered 'the son of the human', or similar, though even recent inclusive versions avoid such steps (cf. NRSV; NIVI). ${ }^{22}$ To object, as

\footnotetext{
${ }^{20}$ Some recent bibliographical items are listed by Ellis, 'Dynamic Equivalence Theory', p. 9 n. 11. This appears to be the main issue at stake in controversies over newer versions such as the NIV Inclusive Language Edition (London: Hodder \& Stoughton, 1995).

${ }^{21}$ The Preface to the NIVI is candid on this point: 'it was recognised that it was often appropriate to mute the patriarchalism of the culture of the biblical writers through gender-inclusive language when this could be done without compromising the message of the Spirit' (p. ix). But a first principle was to retain the 'gender used in the original languages for references to God, angels and demons'.

${ }^{22}$ But at Dan 7.13 the NRSV has 'one like a human being'. Commenting on Mark's gospel, Joanna Dewey uses the phrase 'the Human One' ('The Gospel of Mark', in E.S.Fiorenza [ed.] Searching the Scriptures vol.2: A Feminist Commentary [London: SCM, 1995] 470-50; here p. 477). There is of course a huge
} 
Ellis does - 'In English the word "man" may refer specifically to the male or to the individual and the corporate human being, male and female, black and white, old and young. There is no other term fully equivalent to it. ${ }^{23}$ — is simply to utter a reactionary call to preserve what are becoming (and for good reason) archaisms in our language. Language is always evolving, and there is no more reason to preserve the 'generic' use of the term 'man' than to preserve King James archaisms like 'thee' and 'thou'. ${ }^{24}$ But this current evolution, enmeshed as it is with political interests and commitments, is unsurprisingly contested: the generic use of the term 'man' both reflects and supports a social system in which the male gender is definitive, visible, preeminent; to change the language is to disrupt the system, with all its established relations of power and social organisation.

Still more tricky are cases where the original uses a masculine term in what may well be an inclusive sense. Probably the most obvious New Testament example is the address adelphoi, 'far and away Paul's favorite way of referring to the members of the communities to whom he is writing', and common in other New Testament writings too. ${ }^{25}$ Most older translations rendered this 'brethren', while the NIV consistently translates it 'brothers'. The NRSV, with its well-known concern to use inclusive language, translates 'brothers and sisters', though with the footnote 'Gk: brothers' (e.g.

debate about how the phrase ho huios tou anthrōpou should be interpreted (and therefore translated), which complicates matters here.

${ }^{23}$ Ellis, 'Dynamic Equivalence Theory', 8 n. 6.

${ }^{24} \mathrm{Cf}$. the comments on this issue in the NIV Preface, p. vii. I am well aware that some Christians still want to preserve such archaic forms as supposedly reverent forms of address for God, though originally they were merely common forms of speech which have since disappeared from the English language. That heated debate arises over such questions shows how translation inevitably becomes an arena of competing political interests, with reactionary and progressive perspectives deeply opposed to one another.

${ }^{25}$ Robert Banks, Paul's Idea of Community (revised edn; Peabody, MA: Hendrickson, 1994) 50-51; see further David G. Horrell, 'From adelphoi to oikos theou: Social Transformation in Pauline Christianity', $J B L$ 120: 293-311. Matthew, for example, also uses the term frequently (Matt 5.22-24, 47; 7.3-5; 18.15, 21 , $35 ; 23.8)$. 
Rom $1.13 ; 7.1 ; 1$ Cor 1.10 , etc.). ${ }^{26}$ NIVI now does the same. It is almost certainly the case that the address adelphoi was meant to include all members of the Christian assembly, men and women alike, just as were 'generic' uses in older English of the terms 'men', 'brethren' and so on. Consequently, given that 'brothers' is no longer heard as a genderinclusive form of address, the translation 'brothers and sisters', or equivalents, seems appropriate. Another strategy for dealing with such language - choosing alternatives such as 'believer', 'neighbour', 'member of the community', etc. ${ }^{27}$ - is unfortunate insofar as it obscures the extent to which the language of kinship was central to community-definition in both Old and New Testaments. A further question, however, is whether a translation like 'brothers and sisters' begins to obscure the fact that the New Testament writers used masculine terms which reflected their patriarchal culture.

This issue is posed most sharply in cases where the New Testament uses terms that unambiguously refer to male persons, or terms where an 'inclusive' alternative is already available in the original language. For example, Luke a number of times uses the common address andres adelphoi (KJV and NKJV: 'men and brethren'). This can hardly be taken as anything other than a male-focused address, calling the men of a community ('kinsmen') to attend. The NRSV obscures this with its renderings 'friends' (Acts 1.16), 'fellow Israelites' (Acts 2.29); the NIVI favours 'brothers and sisters' (Acts 1.16; 2.29); the NIV translates 'brothers', as do the NRSV and NIVI when the context may be taken to imply that a specifically male group is in view (Acts $2.37 ; 7.2$ ). Similarly, the word huios can hardly mean other than 'son', especially since Greek has other words a writer could use for the more 'inclusive' term 'children' (tekna, paidia). Paul, for example, uses both these latter terms, as in 1 Cor 14.20 ('do not be children [paidia] in your thinking') or 1 Cor 4.14 ('to admonish you as my beloved children [tekna]'). He refers to Christians

\footnotetext{
${ }^{26}$ But does the footnote confuse the issue here? If adelphoi really means all members of the assembly, male and female, then one may question whether, in contemporary English, it is accurately rendered 'brothers'. The English word 'sibling' might be a useful possibility, though it is less common in everyday parlance. Perhaps the note should simply state 'Gk: adelphoi', though this would of course be merely baffling to those without Greek.

${ }^{27}$ For these renderings of the Hebrew 'āch and the Greek adelphos, see NRSV e.g. Deut 15.2-3, 7-11; 1 Cor $6.6-8 ; 7.12 ; 8.11$ etc.
} 
as 'children of God' (tekna theou: Rom 8.16-17, 21; Phil 2.15; cf. Rom 9.8). But he also refers to Christians as huioi theou, 'sons of God' (Rom 8.14; Gal 3.26; cf. Rom 9.26). These latter references are all rendered 'children of God' by the NRSV and NIVI; 'sons of God' in the NIV. The inclusive rendering may make more comfortable reading for contemporary readers, sensitive to the issue of gender-specific language. But it obscures what is in the Greek text, prevents readers from pondering some of the theological reasons why Paul might specifically insist that all Christians are sons of God, and prevents them from seeing — perhaps to their discomfort — that this text (like many others) does express things from a male point of view, with all the difficulties that brings.

One of Ellis's criticisms of dynamic and specifically inclusive translations is that they conform 'biblical language and concepts to the modern culture rather than conforming the modern culture to biblical language and concepts' ${ }^{28}$ Just as the translators of the KJV 'provided the church with a Bible that transformed the English language to biblical terms and concepts' so, he suggests, in today's more secular culture 'it is even more incumbent upon translators to retain the often strange language of the Bible in order to seek again a similar transformation of our culture'. ${ }^{29}$ I agree with the first part of this last statement. Indeed translators should retain the 'strange' language of the Bible, a strategy that will make the text less comfortable to our ears, less appealing, less domesticated. But whether this should serve the task of conforming our culture to that of the Bible - with its patriarchal presuppositions, its ancient views of disease, its curses, violence, 'holy' war, death penalties, and so on - or rather the task of problematising the Bible is a moot point. Part of the value of an encounter with the 'strange' world of the Bible may certainly be, in William Countryman's words, that it can 'relativize the present', can destabilise our taken-for-granted world and render it strange. ${ }^{30}$ But whether it would be desirable or possible to envisage some kind of return

\footnotetext{
${ }^{28}$ Ellis, 'Dynamic Equivalence Theory', 9.

${ }^{29}$ Ellis, 'Dynamic Equivalence Theory', 11.

${ }^{30}$ L. William Countryman, Dirt, Greed and Sex: Sexual Ethics in the New Testament and their Implications for Today (Philadelphia: Fortress, 1988) 238.
} 
to the values of biblical culture is highly debatable. ${ }^{31}$ Nonetheless, making clear the extent to which the Bible presumes and promotes a male-centred perspective might at least help to clarify (and perhaps sharpen) the contemporary debate, which might then turn out to be more about different construals of biblical authority than about translation and interpretation.

\section{Pious or vulgar? Did Paul say 'crap'?}

Modern translations of the Bible, often explicitly intended to be suitable for "public reading', i.e. reading in Church, tend to render the text 'decently', but in doing so may, at least on certain occasions, translate it onto a level of respectability which obscures the vulgarity of the original. Sometimes the biblical text itself uses euphemistic phrases, as in 1 Sam 24.3, where the Hebrew phrase lěhāsēk et-raglāyw, 'to cover his feet' (KJV), probably means that Saul went into the cave to urinate or defecate - 'to relieve himself', as the NRSV and NIV delicately put it (cf. also Judg 3.24). ${ }^{32}$ But sometimes the text itself appears to use a vulgarity, as in Phil 3.8. Here Paul describes the marks of his Jewish status and identity as now nothing but skubala, which the KJV rendered as 'dung'. Richard Hays translates this as 'crap'; ${ }^{33}$ 'shit' is another possibility. ${ }^{34}$ Such translations have been disputed, for example by Gordon Fee; ${ }^{35}$ but Fee nonetheless agrees that the word is a vulgarity, so the disagreement comes down, at least insofar as it concerns

\footnotetext{
${ }^{31}$ Not least for the reason articulated so well by Rudolf Bultmann: 'there is nothing specifically Christian about the mythical world picture [of the New Testament], which is simply the world picture of a time now past that was not yet formed by scientific thinking' (Rudolf Bultmann, New Testament and Mythology and Other Basic Writings [London: SCM, 1985] 3).

${ }^{32}$ BDB, 697, explains the phrase thus: 'i.e. with long garments, euphemism for evacuating the bowels, from the posture assumed'. The NKJV is marvellously euphemistic: 'to attend to his needs'. The LXX eisēlthen paraskeuasasthai, 'he went in to prepare himself', probably misses the sense of the Hebrew here. Cf. also mēmē raglēhem (lit: 'water of their feet') meaning 'urine', in 2 Kings 18.27 and Isa 36.12 (Qere), rendered 'piss' by the KJV; see BDB, 565.

${ }^{33}$ Richard B. Hays, Echoes of Scripture in the Letters of Paul (London and New Haven: Yale University Press, 1989) 122.

${ }^{34}$ Cf. John M.G. Barclay, 'Paul Among Diaspora Jews: Anomaly or Apostate?', JSNT 60 (1995) 89-120, here p. 113

${ }^{35}$ Gordon D. Fee, Paul's Letter to the Philippians (NICNT; Grand Rapids, MI: Eerdmans, 1995) 319.
} 
translation, to finding a suitably vulgar and 'common' word to denote dung, excrement, scrap, refuse, etc. ${ }^{36}$ Possibly offensive words like 'crap' tend, of course, to be avoided, no doubt since they are regarded as intrinsically unsuitable for a text to be read in public worship. But that comes close to saying that Paul is 'unsuitable' for reading in public worship and that the task of translators is in part to render him respectable, decent, and inoffensive. Paul is occasionally blunt and rude (cf. also Gal 5.12), and we might gain a more realistic and honest impression of his letters if they were not shorn of their rough edges - even if that made Paul at times uncomfortable and impolite reading. ${ }^{37}$ It is at least interesting to ponder how perception of the character of the Bible might be altered if it were not rendered into 'pious-ese'.

\section{Conclusion}

The foregoing remarks might be (mis)interpreted as an attempt to undermine Christian theological and devotional use of the Bible. That is not their intention. They are intended, however, to present an argument for an approach to translation that would enable/compel English readers to encounter the text in a manner as close as possible to that experienced by those who read it in its original languages - and that, surely, should be one of the key aims of any translation. The Bible is a book intimately connected with its contemporary cultures, in vocabulary, practices, world-views and so on. It is, in many places, not a book of clear and elegant writing but one containing varied styles, some awkward, simple or repetitive, and containing much that is highly open to a range of interpretations. It is not an inclusively-written book that conforms to the canons of contemporary political correctness, whatever we might wish, but one that emanates from, and reflects in its writing, male-dominated cultures. And it is not a book which everywhere meets the standards of decency expected by some of its pious readers. None of this stands against

\footnotetext{
${ }^{36}$ Cf. BDAG, 932; Ceslas Spicq, Theological Lexicon of the New Testament (3 vols, tr. and ed. J. D. Ernest; Peabody, MA: Hendrickson, 1994) 3. 263-65, who suggests, quoting E. Osty, that ' $[\mathrm{t}] \mathrm{o}$ convey the crudity of the Greek', Paul's phrase be rendered “'It's all crap” ('c'est de la crotte').

${ }^{37}$ Translation might thus be one facet, though only one, to be sure, of the 'domestication' of Paul against which Ernst Käsemann so vigorously railed (see e.g. E. Käsemann, New Testament Questions of Today [London: SCM, 1969] 250-51).
} 
theological or devotional use of the Bible, but it does express the conviction that such use of the Bible should, facilitated by more 'honest' translations, take seriously the facets of the text that make it strange and in some ways problematic, that distance it from our expectations and values. The trouble is, no doubt, in a customer-driven age, that such a 'warts and all' translation of the Bible would not be popular. It would be too puzzling, too unclear, too offensive, unsuitable for public reading. ${ }^{38}$

\footnotetext{
${ }^{38} \mathrm{I}$ am very grateful to James Crossley for his comments on a draft of this paper, though the arguments and shortcomings remain entirely my own responsibility.
} 